\title{
Experimental verification of a CFD model for the closed plant factory under artificial lighting
}

\author{
Wei Lu ${ }^{\mathrm{a}, 1}$, Yiwen $\mathrm{Hu}^{\mathrm{a}, 1}$, Shenghan Zhou ${ }^{\mathrm{a}}$, Xin Zhang ${ }^{\mathrm{a}}$, Quan Yuan ${ }^{\mathrm{a}}$, Xiaoting Zhou ${ }^{\mathrm{a}}$, Houcheng Liu ${ }^{\mathrm{b}}$, Jiangtao Hu ${ }^{\mathrm{c}}$, Qichang \\ Yang $^{\mathrm{c}^{*}}$, Yinjian Zheng ${ }^{\mathrm{c}^{*}}$, Yangxia Zheng ${ }^{\mathrm{a}^{*}}$ \\ ${ }^{a}$ College of Horticulture, Sichuan Agricultural University, Chengdu, 611130, China \\ ${ }^{\mathrm{b}}$ College of Horticulture, South China Agricultural University, Guangzhou, 510000, China \\ 'Institute of Urban Agriculture, Chinese Academy of Agricultural Sciences, Chengdu, 610213, China \\ ${ }^{1}$ These authors contributed equally to this work.
}

\begin{abstract}
A computational fluid dynamics (CFD) model for the closed plant factory under artificial lighting has been developed in this study, the experimental verification of CFD model with the air velocity value was compared with the measured air temperature value. The results showed that the mean relative error of validation with the air velocity was $15 \%$, and comparable with experimentally observed air temperature profile inside the plant factory with RMSE of 3\% which show the utility of CFD to study plant factory microclimatic parameters.
\end{abstract}

\section{Introduction}

Plant factory is an important way using scientific management technology to reform Chinese traditional agriculture, is advanced facility agriculture, is an important symbol of the development ability level of our country's economic modernization agricultural enterprises, and is the direction of the development of the world agricultural society in the 21 st century ${ }^{[1]}$. As many years of practice have shown, plant factories have more outstanding advantages than other production methods, which are manifested in strong crop production plans; the yield per unit area can be increased by 30 40 times more than that of open field cultivation ${ }^{[2]}$; no spraying of pesticides and no pollution of the environment ${ }^{[3]}$; high utilization efficiency of land and water resource. Therefore, plant factories are considered as an important way to solve the growing demand of resource shortage and new generation labor shortage in the future ${ }^{[4]}$.

The environmental factors affecting plant production include temperature environment, airflow environment, light environment, humidity environment and carbon dioxide environment ${ }^{[5]}$.

A vital factor of plant ecological environment is the airflow environment, which affects the growth and development process of plants. The suitable air velocity of plant leaves can regulate the microenvironment, while reducing water condensation to avoid high wet diseases, promote crop growth and increase stress resistance, and ultimately improve product quality ${ }^{[6]}$.

The optimum air velocity of indoor potted pepper was about $0.8 \mathrm{~m} \cdot \mathrm{s}^{-1}$, no wind or high wind velocity was not conducive to the pepper growth ${ }^{[7]}$. In the CFD research of plant factories, Zhang et al. ${ }^{[8]}$ establish a three- dimensional model of the single-layer cultivation area of the closing plant factory, simulate and verify the airflow environment of the single-layer cultivation area. Lim et al. ${ }^{[9]}$ established a three-dimensional CFD model for plant factories, analyzed the airflow field by setting different air outlets. Baek et al. ${ }^{[10]}$ took artificial light plant as the research object. They constructed the CFD model in different ventilation modes, and obtained the optimal ventilation mode by comparative analysis. Huan Liu et al. ${ }^{[11]}$ used CFD to establish plant factory environment model. It is reasonable and feasible to use Fluent methods to simulate and optimize the airflow field in plant factories.This experiment simulated and verified the airflow field of indoor artificial light plant factory by using CFD.

\section{Materials and methods}

\subsection{Experimental materials}

(1) ANSYS Fluent 16.0 software was used to simulate the indoor airflow in plant factory.

(2) The simulated value was compared with the measured value of air velocity to verify the accuracy of the model. The airflow uniformity was studied by this model.

\subsection{Experimental methods}

\subsubsection{Establish CFD model of indoor artificial light plant factory}

(1) Establish CFD geometric model In the ANSYS Workbench 16.0, the three-dimensional 
geometric model of plant factory was established (4800mm(Length) $\times 2800 \mathrm{~mm}$ (width) $\times 2600 \mathrm{~mm}$ (height) ; the top inlet was simplified to a side length of $400 \mathrm{~mm}$ square; and the two sides of the wall were simplified to nine return vents $(600 \mathrm{~mm} \times 200 \mathrm{~mm})$.

(2) Calculate the aerodynamic model

A standard k- $\varepsilon$ turbulence model was used to solve the turbulent transport process of indoor air, and the flow near the wall adopted the standard wall function method.

(3) Numerical simulation

The computational grid was divided in the ANSYS Workbench 16.0, and the whole fluid region was divided into structured hexahedral meshing. After grid independence test, the number of grids was calculated to be 3521452, and the grid quality is excellent (Quality $=0.999$ ).

(4) Steady-state calculations

The calculation was carried out in FLUENT 16.0 software in ANSYS Workbench.

\subsubsection{Model validation}

This experiment selected the section $X=1.2 \mathrm{~m}$, and 4 measuring points evenly at each height $\mathrm{Y}=0.5,1.5,2.0 \mathrm{~m}$. So, there were totally 12 measuring points (V1 V12). The 12 measuring points in this section were used to measure the airflow velocity for simulation and verification. Air velocity measurement: DT-618 hand-held anemometer $( \pm 3 \% \pm 0.1 \mathrm{~m} \cdot \mathrm{s}-1)$, data acquisition: record every $10 \mathrm{~min}$.

\subsubsection{Simulation of the airflow uniformity in the plant factory}

The experiment introduced the Fluent calculation results into CFD, simulated and obtained the airflow distribution of the plant factory, and analyzed its uniformity.

\subsection{Data statistics and analysis}

In this experiment, Excel 2016 software was used for data processing and error analysis.

\section{Results and discussions}

\subsection{Comparison of air velocity between simulated and measured values}

The measured values of 12 measuring points were compared with the simulated values, and the results were shown in Figure 1. Point 4 was located near the outlet, its absolute error and relative error was the largest, respectively $1.1 \mathrm{~m} \cdot \mathrm{s}-1$ and $4.6 \%$. The absolute error of Point 12 was $0.1-0.6 \mathrm{~m} \cdot \mathrm{s}-1$, the relative error was $2 \%-35 \%$, the mean absolute error was $0.2 \mathrm{~m} \cdot \mathrm{s}-1$ and the mean relative error was $15 \%$, the model was effective.

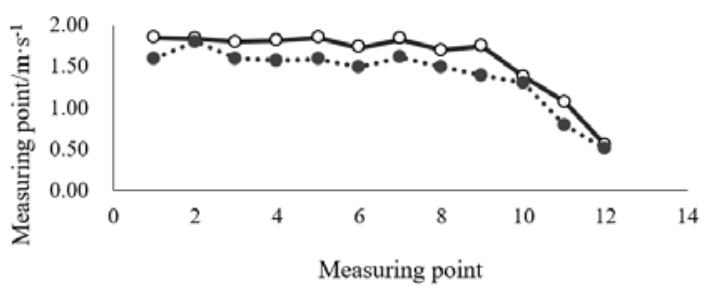

Fig. 1 Comparison of air velocity between simulated and measured values

\subsection{Analysis of airflow uniformity}

By experimental verification, it was concluded that the average absolute error between the simulated value and the measured value of the air velocity measuring points was $0.2 \mathrm{~m} \cdot \mathrm{s}-1$, the average relative error was $15 \%$. The model was correct, which can be used for the analysis of the airflow uniformity.

The model results showed that the minimum air velocity was close to $0 \mathrm{~m} \cdot \mathrm{s}^{-1}$, the maximum air velocity in the lower cultivation area near the inlet, was $0.4 \mathrm{~m} \cdot \mathrm{s}^{-1}$; the air velocity in $90 \%$ of the cultivation area was less than $0.3 \mathrm{~m} \cdot \mathrm{s}^{-1}$, the distribution of the airflow was not uniform.

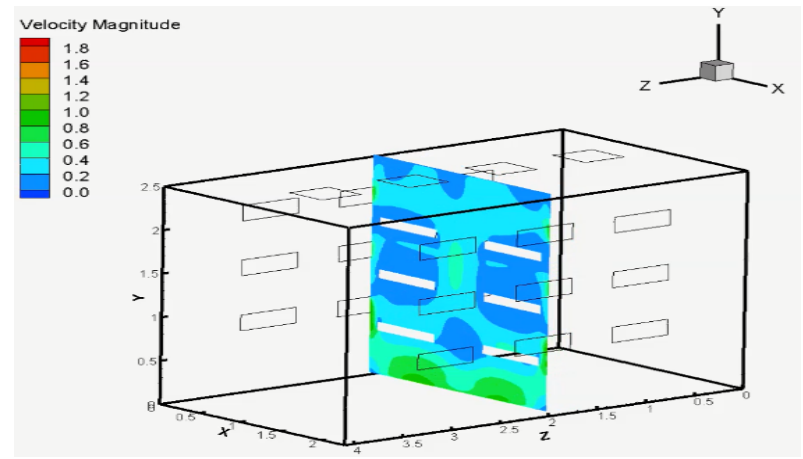

Fig. 2 The airflow velocity distribution at interface $\mathrm{Z}=2.0 \mathrm{~m}$

\section{Conclusions}

It was concluded that in this ventilation mode, the airflow of the plant factory entered the room vertically from the upper inlet, accumulated at the inlet, and formed eddy and rotational flow at the ground of the plant factory, which was consistent with the research results of Huan Liu et al. Under the current ventilation mode, only $10 \%$ of the cultivation area was in the range of suitable growth air velocity $(0.3-1.0 \mathrm{~m} \cdot \mathrm{s}-1)$.

\section{Acknowledgements}

This work was sponsored through the Research Fund for the Students' Innovation and Entrepreneurship Training Program of Sichuan Province(Grant No. 1921996490). 


\section{References}

1. Yu, X.S., Liu, Y.P. (2013) Development and Prospect of Plant factory Cultivation Technology. Agricultural Outlook, 7: 57-60.

2. Li, M., Wang, Z.Q. (2016) Technological Prospect of Artificial Light plant Factory in the Era of intelligent Production. Agricultural Engineering Technology, 36(10): 16-19.

3. Yang, Q.C., Liu, W.K. (2014) New progress of global plant factory. Journal of Lighting Engineering, 25(4): 4.

4. Yang, Q.C., Wei, L.L., Liu, W.K. (2012) Plant Factory System and Practice. Chemical Industry Press, Beijing.

5. Zhao, X.H., Sun, C., Shi, Z.M., et al. (2018) Research on the development Trend of related cultivation technology in plant factories. Times Agricultural Machinery, 10: 34.

6. Pan, R.Z. (2011) Plant Physiology. Higher Education Press.

7. Li, X., Wang, G.D., Xue, X.Z., et al. (2008) Effects of different wind speeds on the growth and transpiration of potted sweet pepper in greenhouse. Chinese Journal of Agricultural Engineering, (S2): 214-218.

8. Zhang, Y., Kacira, M., An, L. (2016) A CFD study on improving air flow uniformity in indoor plant factory system. Biosystems Engineering, 147: 193-205.

9. Lim, T.G. (2014) Analysis of airflow pattern in plant factory with different inlet and outlet locations using computational fluid dynamics. Biosystems Engineering, 39(4): 310-317.

10. Baek, M.S., Kwon, S.Y., Lim, J.H. (2016) Improvement of the crop growth rate in plant factory by promoting air flow inside the cultivation. International Journal of Smart Home, 10 (2): 63-74.

11. Liu, H., Fang, H., Cheng, R.F., et al. (2018) Simulation and Optimization of flow field and temperature field in artificial light plant factory based on CFD. Journal of China Agricultural University, 23(5): 108-116. 